\title{
The Curative Power of Play: The Voices of Therapists around the World*
}

\author{
Nancy Riedel \\ Bowers \\ Wilfrid Laurier \\ University, Ontario, \\ Canada
}

\author{
Winnie Pak Wan \\ Yeung \\ Saint Paul University, \\ Ontario, Canada
}

\author{
Anna Lee Bowers \\ Univesity of Toronto, \\ Ontario, Canada
}

\begin{abstract}
It is important for all therapists to be culturally sensitive to children and their eco-systems as well as to be aware of the current trends and the changing application of play as a healing agent. The focus of this study is on the development of a current description of play by therapists from a global perspective through a thematic analysis of focus groups resulting in an explanation of how play contributes to healing and the practice of therapy. In this study, the naturalistic method of qualitative research (Bowers, 2009; Lincoln \& Guba, 1985) was applied to the study of play around the world, resulting in a new description of "play". The analyses of focus group meetings in Morocco, Singapore, Hong Kong, Canada and Europe resulted in the emergence of 8 themes: productivity through play, contribution to development, facilitation of the relationship through play, honouring diversity, collaboration between children and caregivers, stimulation through technology-based play, relaxation provided by play, and the devaluation of play. These themes, which are presented through the "voices of the participants", together with the literature review, serve to enrich the changing description of play. With participants from all continents, a current global perspective highlights the changes that play, both as a concept and as a healing agent, has undergone and will continue to do so. New information emerged suggesting that technology has become a worldwide focus for children but has a paradoxical effect on their relationships.
\end{abstract}

Keywords: collaboration with play, global perspective, productivity, technology, relaxation

\section{Introduction}

Therapists serve a vital function in the lives of children who experience psycho-social difficulties. It helps vulnerable children deal with their developmental issues, to regain mastery and to be able to function normally again (O’Connor, 2000). The Ecosystemic Play Therapy (EPT) model highlights the focus for healing on "the total child within the context of the child's ecosystem” (O’Connor, 2000, p. 87). This model integrates many

\footnotetext{
*Acknowledgements: The authors would like to thank Melanie Chalebois and Selda Sezen of Wilfrid Laurier University for their contribution to the thematic analysis.

Nancy Riedel Bowers, RSW, Rpt-S, Ph.D., Part-time Faculty, Faculty of Social Work; Associate Professional Faculty, Seminary, Wilfrid Laurier University. Email: nriedel@wlu.ca

Winnie Pak Wan Yeung, Ph.D. (can.), MDiv., Faculty of Human Sciences, School of Counselling, Psychotherapy and Spirituality, Saint Paul University.

Anna Lee Bowers, Ph.D. Student, M.A., School and Clinical Child Psychology, Department of Applied Psychology and Human Development, Ontario Institute for Studies in Education, University of Toronto.
} 
treatment modalities and theories into a single model (Boyer, 2010) and considers the impact of the whole ecosystem of a child - the biological, economic and psychological factors-observing how the interactions between the clients and their family and/or the cultural social system affect the development and pathological behaviours of the clients.

O’Connor (2000) calls upon therapists to develop cultural competency, so that they will be sensitive to cultural variation in play practices and will develop culturally related awareness, skill and knowledge of their clients. Therapists must have knowledge about the historical, psychological, sociological and political background of their clients, so that the treatment approach is in harmony with the belief and values of their clients, their families and communities, without creating further distress to them (Boyer, 2010). To be effective, therapists must be aware that the definition of play continues to evolve relative to changing times and cultural changes.

The study at hand provides a new description of play through the data collection and analysis of focus and individual interviews consisting of play therapists around the globe. The results of the thematic analysis stress the need for sensitivity to diversity by all therapists who work within the ecosystemic context of the nested systems. Therapists can impact the "total child" within the context of the child's ecosystem (O'Connor, 2000, p. 87) when they understand the perspectives of caregivers, school, society and culture on play vis a vis the child.

\section{Meanings of Play: Past and Present}

Play is a common activity and universal activity for children around the world (Russ, Fiorelli, \& Spannagel, 2011), and yet a precise operational meaning of play has historically been difficult to achieve. Brian Sutton-Smith devoted his career to the scholarly works on play and after six decades of the study of play, his work was recently represented in the New York Times suggesting that there is no single definition that captures what the meaning of play entails (Fox, 2015). However, there has been sporadic attention devoted to this phenomenon over the past 75 years and the concept of play continues to be defined in many ways, and continues to be discussed within a variety of contexts, with enhanced attention by the media and public viewing.

The profound importance of play to the child's growth and transition to adulthood, as well as to human growth and emotional healing, has become increasingly understood (Brown, 2010; Perry \& Szalavitz, 2007). The recognition of the effects of play on brain development is currently creating excitement as to how play impacts and is impacted by brain activity across the lifespan. Young children grow naturally through play with their "voice" being represented through play. Considering the "restrictions of verbal interactions with young children" (Goodman, Reed, \& Athey-Lloyd, 2015, p. 34), play, as part of their natural development, is intrinsically associated with children and historically connected with early education and learning in childhood (D’Angour, 2013).

An examination of the history of play reveals that play has been innate to many generations of civilization. In ancient Greece, play (“paidia”) was intrinsically associated with children (“paides”). Plato recognized "that play influenced the way children developed as adults” (D’Angour, 2013, p. 293). Furthermore, Meares (1993) comments on the implication of play in the development of the person through the statement:

Artifacts from the earliest civilizations include miniature representations of people and animals, presumably used as toys. It is difficult not to conclude that the capacity of play is part of our genetic endowment, just as the potential for language creation is biologically given... this capacity depends upon the responsiveness of the environment (p. 151).

Play is significant to human development. Children acquire new experiences and skills through play. It builds up their character, teaches them how to cooperate, and helps them develop social, emotional and 
intellectual skills that assist in their integration into a complex society. These are skills they could not be acquired in other ways but through play (Elkind, 2008; Sutton-Smith, 2008) as play is the natural medium of express for the child (Axline, 1947).

Further examination of the meaning of the concept "play" offers an explanation of its value in the growth of the child. The etymology of this term originates within the context of fighting and game playing. Mahon (1993) reviews the origin of the word "play":

Whereas the modern definition of play as "games, diversion" captures the lucid nature of the activity, the word derives from the Old English plega, which implied a less sportive intent-to strike a blow (asc-plega = playing with spears, that is, fighting with spears; or sword-plega = fighting with swords (Skeat, 1910))... If we follow these etymological leads, play would seem to have begun with actions that were anything but "playful" in the modern usage of the word (p. 173).

Further examination of the origin of the word "play" is presented in old/middle English, the earliest known in 1225, as recorded in an 1873 manuscript, Old English Homilies (Morris, 1981). Earlier citations in AD973 and AD1150 are noted in old Germanic root words. With limited access to accurate translations, the recognized early representation of the concept of play is noted as part of the development of the human being. Play was a contributor to the evolution of education, which was not evident until the beginning of the Hellenistic period.

Modern dictionaries have offered a variety of definitions over the past many years that incorporate the game aspect of play implied in the original meaning of the word play along with other variations on this theme. Webster's Ninth New Collegiate Dictionary (1989) suggests that the meaning of play is "the spontaneous activity of children” (p. 902). The Oxford English Dictionary (1989) emphasizes play "as exercise, brisk or free movement or action” (p. 1011) and as "unimpeded movement” (p. 1012). Merriam-Webster.com (2012) suggests that play is "a state of being active; operative and relevant; free and unimpeded motion" and as "relaxation” (Merriam-Webster.com, 2015). These definitions, along with other current ones, highlight the "freedom" afforded by the process of play as well as "spontaneity" and relaxation as recurring description associated to the meaning of play.

It is difficult to attain a unifying definition of what play is because of the complexity of human behaviours involved in the act of play. The form and process of play is unpredictable, there is a diversity of the cultural values that inform play, and there are a wide variety of objects that people play with (Henricks, 2008). Technology, the economic climate, changes in the role of women, work patterns, demands of school and work, and parental and caregivers' involvements further reinforce the difficulty of how we come to define play (Roopnarine \& Davidson, 2015). There is an ever-changing nature and unpredictability to the process and meaning of play.

Sutton-Smith (2008) defines play as a dynamic, ever-changing process that is filled with ambiguity and surprise. Henricks (2008) describes it as "a subtle, elusive phenomenon that seems to appear without notice and then disappears just as quickly” (p. 160). Therapists require an awareness that play evolves as time, culture and technology changes when utilizing play in the treatment process.

Play is evolving, with the player having freedom to make choices as to how they play; they can do things in play that may not be allowed in the real world, which in turn makes life more creative and bearable (Henricks, 2008; Sutton-Smith, 2008). It is becoming clear that play allows children to "find ways to show their interests and talents, express their feelings, practice growing up, experience their own identities, develop a sense of self and others, rehearse social roles and strive to understand their real world” (Gold, Grothues, 
Jossberger, Gruber, \& Melter, 2014, p. 147). To this end, technology has taken on a whole new meaning in the application of play for healing.

\section{The Impact of Technology on Play and Therapy}

Computer technology has become an integral part of our lives, and it impacts the form of play, the development of children and how therapy is conducted. Many children have mastered devices like the iPhone, iPad and handheld gaming consoles. Video games and technological resources can teach children complex tasks and skills, such as enhancing vision, learning, and brain plasticity (Eichenbaum, Bavelier, \& Green, 2014). Facebook has helped young people connect and develop their ability to use apps in order to enhance their development and personal agency (Boyd, 2014). Social media allows them to experiment and work out their identities and to deal with personal hardships (Boyd, 2014; Gardner \& Davis, 2013). Between 2004 and 2009, there was a dramatic increase in media use by consumers due to the burgeoning abundance of online and mobile media (Rideout et al., 2010). In 2012, the market for video games brought in more than sixty billion dollars in global revenue, and this is forecasted to grow to $\$ 82$ billion by 2017 (Gaudiosi, 2012). Researchers have found that 8 to 18 year-olds spend more time consuming electronic media than any other activity, except for sleeping (Rideout et al., 2010). They average more than $7 \frac{1}{2}$ hours a day of media consumption, seven days a week. This number of hours increases for children who multitask across multiple devices. They pack a total of 10 hours and 45 minutes worth of media content into their daily $7 \frac{1}{2} 2$ hours of media consumption (Rideout, Foehr, \& Roberts, 2010). However, the inclusion of technological play within the daily lives of children and families varies worldwide.

In a cross-national study of twenty-four hundred children in sixteen countries across five continents, caregivers expressed concern that their children were lacking time spent engaging in outdoor and imaginary play with $27 \%$ of mothers reporting that their children engaged in imaginative play (Singer, Singer, D’Agostino, \& DeLong, 2009). Fear about issues of privacy and confidentiality around technological play was expressed (Gardner \& Davis, 2013) contributing to a growing concern and paradoxical effect of technology.

Researchers, parents, policy makers and play therapists are interested to know more about how interaction with technology shapes children's development, structures their relationship to their caregivers, and whether caregivers should enable or limit children's involvement with technological play (Boyd, 2014; Gardner \& Davis, 2013). In May, 2012, 113 members of the Association of Play Therapy responded to a survey “Technology: Will Play Therapy Harness It or Be Mindlessly Driven by It” conducted by Association of Play Therapy and its Technology Task Force to investigate the use of technology in the play room. Participants acknowledged that technology has become an integral part of children's lives. It provides good resources, but there are concerns of privacy and confidentiality and de-personalization.

Pykhtina (2014) asserts that "trying to keep technologies out of the therapy setting is unrealistic and will ultimately be counterproductive” (Pykhtina, 2014, p. 4). Using iPad and associated apps within the playroom is a new concept and, at the same time, leaves concerns by some that technology can interfere with the therapeutic process. Technology has a potential to exclude the therapist or prevent the therapist from building alliance with the child (Pykhtina, 2014, p. 4), although Snow and colleagues (2012) posit that age appropriate apps can give children the freedom to make choices. For example, a computer tablet can help children express difficult and painful feelings (Snow, Winburn, Crumrine, Jackson, \& Killian, 2012) leaving the idea that there are creative and helpful usages of technology in education and healing. 


\section{Involvement of Caregivers in the Treatment Process}

Ecosystemic play therapy includes caregivers in the therapeutic process in order to ensure solid change over time (Boyer, 2010). However, the attitudes of caregivers around the world can be very different. Some caregivers think play is just for fun or a "waste of time" (Elkind, 2008, p. 3). They are preoccupied with "real-life" and neglect to consider the benefits of leisurely play on the social, emotional, and cognitive development of their children (Elkind, 2008; Roopnarine \& Davidson, 2015). According to Lancy (2007), caregivers consider play as an opportunity to jump start academic preparedness. They see play as a means for children to acquire skills that prepare them for future academic achievement and success. They are increasingly using social media and technology to facilitate this process as a way of or as opposed to joining in the learning process by engaging in play with their children. Therapists face obstacles when engaging caregivers in the therapeutic process with their children through play.

As seen in the application of healing through play around the world, whether it is through psychotherapy, counselling, or community and group play therapy, there is a need for awareness in the area of cultural competency (Penn \& Post, 2014). Therapists have to acquire knowledge of the ecosystems of the children, their families, communities and skills to work with them, in order to foster healthy development and well-being (Boyer, 2010). The study at hand was designed with this query in mind. Specifically, how is "play" seen around the world, what values does it promote for the life of the child within the family and systems, how is the current description of play changing, and how will the new description impact the practice of therapy?

\section{Methods}

The research questions posed for this study are: (1) What are the themes of play from the global perspective? (2) How is play being described around the world? (3) How does the new description of play contribute to healing in the practice of therapy?

To answer these research questions, thereby providing a better description of play from a global perspective, the naturalistic inquiry method was applied. This qualitative approach to data analysis as described by Lincoln and Guba (1985) was chosen for this study to provide a better description of the curative powers of play around the world and new definitions of play. The mutual interaction of the interviewers (play therapists) and participants (play therapists) is encouraged through this methodology. The grand tour question, "What is play in your part of the world and how does it contribute to healing?" was posed by interviewers in each location. Transcriptions of each focus group interview then took place. Coding and thematic analysis followed, and the "new information" that emerged through the data was summarized to reveal participant narratives.

\section{Participants}

The study began with the Research Ethics Board of Wilfrid Laurier University, Waterloo, Ontario, Canada approval to conduct a focus group of voluntary participants at an international conference of play therapists in Marrakesh, Morocco. The group occurred at a time and place convenient to all those who responded to a poster asking for interested play therapists to participate in this research study. The 10 members of the group represented 5 continents of the world, and consisted of 8 women and 2 men. All were similarly trained in play therapy and all received the ethics letter indicating the intentions of the study, the researcher and supervisor's information, and indications of confidentiality of all data at all times. 


\section{Data Collection}

The snowball approach (Lincoln \& Guba, 1985) of locating participants for this study led to interviews in Africa, Asia and North America providing for a rich data collection process. Additional ethics approval was sought and received to expand the study to Singapore and Hong Kong where similar focus groups took place. The final step of the data collection process involved individual and telephone/skype interviews, which took place to test the reliability saturation of data results.

The focus groups in each location were scheduled for 3 to 10 people, with a combination of male and female representation, but all were play therapists. The interviews were 1 to 2 hours in length, all taped for transcription purposes with permission obtained from all participants. Trustworthiness or "accuracy of the account” (Creswell, 1994, p. 156) was addressed through triangulation, member checks, and peer debriefing.

\section{Data Analysis}

Transcripts of interviews were prepared by neutral people to ensure objectivity with the acquired data. Attempts were made to find convergence among the sources of information through the discovery of codes, categories, and emerging themes that "identify recurring ideas or language and patterns of belief (that) link people and settings together” (Marshall \& Rossman, 1989, p. 116). The process was additive, combining codes into typologies (Glaser \& Straus, 1967). Through repeated readings of the transcripts (Braun \& Clarke, 2006), and with hand done notation throughout these readings, a familiarization with the data was accomplished in conjunction with the development a unique data analysis system. Within this study, an eventual emergence of themes and theory developed (Cho \& Lee, 2014), allowing for the discovery of "new information" (Lincoln \& Guba, 1985). Extended immersion in the data over a number of months following the final interviews allowed for a saturation point to be reached.

\section{Results \& Discussion}

Eight themes arose from the coding and categorization of the focus groups' transcripts based on the responses from the "grand tour question": What is play in your part of the world, how does it contribute to healing and how is the description changing? The evolving discussions in the form of focus groups and individual interviews took place in Africa, Asia, Europe and North America with eventual themes developing from the data. As explained by Braun and Clarke (2008), "A theme captures something important about the data in relation to the research question, and represents some level of 'patterned' response or meaning within the data set” (p. 82). The themes that emerged from the data collected worldwide are herein presented with "verbatim accounts" incorporated in italics with incorporation of the aforementioned literature along with newly acquired references as the themes emerged.

\section{Productivity through Play}

Play is considered by many scholars to be an opportunity for children to learn and develop themselves (Taylor et al., 2004; Krakowski, 2012). Through play, children learn to make sense of their world and everything in it. Due to various pressures from school and work, many caregivers focus on productivity, believing this to be the functional aspect of play. This is especially true for those who consider play to be for slackers (Elkind, 2008). Play is viewed as children's work because it supports their cognitive, social and emotional development (Gaskin, Haight, \& Lancy, 2007). It becomes an opportunity for them to learn and develop skills for self-advancement, personal and social progress (Henricks, 2008; Elkind, 2008). In this study, 
participants expressed that engaging in play is for functional and productive purposes, such as to learn some knowledge, to have a good result in academic, to gain a sense of mastery, to increase the level of confidence and self-esteem, to promote self-expression and to improve self-regulation. The focuses of the caregivers in regard to play are on their children's performance, accomplishment, and productivity, because without these, play would be "a waste of time". With parental control, the play that their children involved are directed, controlled, and organized by adults. The children are playing what the adults play. It can be labelled as "play work" by the research participants. "Play work" involves activities that are educational, helping children to improve literacy skills or numeracy skills without spontaneous play. Spontaneous play is a kind of play that is spontaneous, just happens, comes from within the child, and is innate. Children are born to play; they engage in play very quickly.

Participants expressed that many caregivers that they have encountered were inclined to have their children participate in structured learning activities to boost productivity, such as ballet, hockey, soccer, baseball and piano, etc. The aim is to get more credentials or certificates. There is a strong emphasis on cognitive learning and competitive skills but less for free play with engagement of imagination and fantasy. Play becomes games of skill and achievement training (Sutton-Smith, 2008). Leisure play in healthy development has become an unaffordable luxury (Elkind, 2008). Participants expressed that spontaneous play is lost in our world.

\section{Contribution to Development}

Participants asserted that the "non-structured play" provides children the opportunity to learn negotiation skills. They learn who is going to take charge; who is taking turn sharing resources, which are important for their developmental growth. They also learn risk taking by sharing play materials and interacting socially. Play also encourages exploration, and team work. It promotes social skills, problem-solving skills and develops self-awareness. Children learn to play by the rules, building on each other's strengths in building forts, playing ball in the park, which engages everyone. It stimulates their brain processing.

In therapy, not all children that come are team players. Many struggle and do not know how to be part of the team. Some would rather work on their own, which gravitate toward isolation, without interacting with others. Some children have not been to school. They are stuck in parallel play. They play beside the next person, but do not want to interact.

When children engage in play, they gain new skills, experiences, and knowledge as part of their age appropriate social, emotional, cognitive, intellectual, and language developments. Play fosters their character and assists them in the development of skills that improve their integration into a complex society (Elkind, 2008; Sutton-Smith, 2008).

\section{Facilitation of the Relationship through Play}

Three sub-themes of relationship enhancement through play are evident from the data in this global study. Relationship is a time of "connecting", facilitating engagement with a diverse context vis a vis the attachments that play affords within communities around the world. Using direct quotations, the game to connect... a way to engage (children and families) is seen by some as particularly useful for healing relationships while at the same time, in the same communities, parents do not see the importance of engaging in play activities with their children. Rather, they offer technological connectors to provide stimulation and to pass time. The paradox of technology with some advanced and enticing video games is that (electronics) are helping children make 
connections... something they can talk to, albeit without connecting face to face. Essential to the development of children is the development of negotiation skills... self-awareness, around rules and strengths. For the minds of many, this can be accomplished through viral relationships. For some, play is relational... establishing relationships, encouragement to get (children) to take risks... it takes a lot of encouragement to get them to risk, using play materials that are around them... or play materials that interact with social. Attachments are formed around the world through play, as is indicated by all participants but it is done through different means and for different reasons. Play represents the voice of the child (Bowers, 2013), while facilitating social, emotional, and intellectual skills (Elkind, 2008; Sutton-Smith, 2008).

Participants expressed that in therapeutic settings, some therapists are comfortable in establishing relationships with the clients, whereas others are struggling with it. Participants believe that relationship has to be part of that healing process because many clients were rejected throughout their lives. Clients came back because they felt safe with the therapists. Therapists provide safety and hold the experience and journey with clients, trusting that they are going to work through their issues. For some clients, it took a long time for healing. Sometimes, something big came up in the middle of processing, which was hard for (therapists) to watch. The therapeutic process was not a smooth journey. Nevertheless, with authenticity, honesty, maintaining good boundary, through supervision, good self-care and play, therapists are able to hold those experiences.

\section{Honouring Diversity}

The concept of diversity is pivotal and essential in any conversation about the meaning of play (Henricks, 2008), because we live in the ever-changing world. The meaning of play is contextualized and incorporated into the lifestyle of communities around the world (Roopnarine \& Davidson, 2015). O’Connor (2000) asserts that pathological behaviours of the clients can be influenced by their interaction with their family, the larger diverse cultural and social system.

The theme of diversity is evident throughout this research. Play is expressed in different forms and different activities among different age groups, communities and cultures. Adults engage in play such as woodworking, quilting and the gym, for purposes of fun, relaxation and accomplishment. Men and women dealing with grief, stress or anxiety turn to play to help. Hospice, shelters and hospitals have playrooms for children, offering a play environment to facilitate healing.

Over the last 25 years, there is wider acceptance and knowledge of play therapy as a means of helping children work through difficult problems, strengthening individuals' self-esteem and their community identity. Sandtray brings healing to children who have experienced trauma as it allows them to externalize their experiences and to find resolution to their difficult problems and traumas instead of having repetitive play. Play serves a function for vulnerable individuals, making life more fun, creative and bearable (Hendricks, 2008; Sutton-Smith, 2008).

Play evolves with time, culture, and technology. There is diversity in the objects of play (Hendricks, 2008). Play may involve toys, but these are not essential. Play can be spontaneous or well-planned, indoor or outdoor, structured or non-structured. It can involve a wide variety of objects and activities, including board games, sports, nature, music, art, pets, and video games.

Play brings healing to a diverse population. In groups such as sports teams, individuals find belonging, acceptance and value for their contributions. Playing in a group is viewed as an important step in childhood socialization as this builds relationships and a sense of security. 
Hendricks (2008) asserts that the diversity of cultural values informs what play looks like, influencing how children and adults engage in the playing process. Play therapists must find congruence between the clients' cultural experience and the therapeutic treatment goals and intervention (Boyer, 2010). The choices of play and toys in the therapeutic session must be compatible to the clients' cultural background, their values and beliefs in order to promote healing.

\section{Collaboration between Children and Caregivers}

Therapists may consider engaging caregivers in the therapeutic process in order to ensure solid, lasting change (Boyer, 2010). So the attitude and personal views of caregivers on play is important, for they have direct impact on their children in the therapeutic process.

Some caregivers consider play as solely a child's activity, leaving children alone to play with "very little" adult involvement. Other caregivers consider play as a way to improve cognitive and social abilities that are crucial for achieving academic success at school (Chessa, Lis, Riso, Delvecchio, Mazzeschi, Russ, \& Dillon, 2013; Parmar, Harkness, \& Super, 2004). Play without direct involvement from caregivers limits the opportunity for direct eye-to-eye communication. The chance to exchange affection, care, and intimacy become scarce. This condition is exacerbated when both caregivers have a full and busy work schedule, limiting opportunities for children to build secure attachments and develop their identity and self-esteem. For caregivers who play with their children, play is often structured rather than free play-seeing play times as opportunities to educate children. Consequently, caregivers and their children are often not on equal ground. Thus, it may hinder the treatment process. Participants consider feelings and experiences contained within one room, one time period with one person not as healing. Play therapy experience is rich; it cannot be isolated in that one little room... It is not the healing power expressed eco-systematically. A participant in one location expressed that she would not do therapy without parents in the room, unless the parents are the source of the problem. Parents know their child better than the therapist would. Therapists would have parents in the room, so they would align with them. Parents then benefit from modeling with the therapist. It is very positive.

\section{Stimulation through Technology-Based Play}

In this study, electronic games have become the first choice of play activity for most children because of their enticing qualities. Players can play independently and, at the same time, connect with strangers. Those who are socially inept can communicate and engage with others in games, giving them a sense of belonging. However, there are concerns with technology-based play. Electronic games captivate players' continuous attention, put players in a passive role, and can become a child's single focus and primary activity. This kind of play could foster dependency on electronic games which have an addictive quality. Technological play may also replace pretend play—important for development of social skills in children (Chessa et al., 2013) —and reduce opportunities to learn relationship building, social skills, and negotiation skills. Furthermore, children may gravitate towards passive entertainment instead of active face-to-face play experiences. Many caregivers were concerned about the violence in some of these video games and the amount of time their children spend playing them. Elkind (2008) argues that nothing can replace human contact and the need for relationships. It is important to remember that technology has its merits. It can be useful in helping children disclose their abuse and pain in the therapy room (Snow et al., 2012). To date, few studies have examined technological play and its impact on children and teens (Pykhtina, 2014). 


\section{Relaxation Provided by Play}

Participants acknowledged the role of play in making people relaxed. Moving one's body whether through free play, retreating to nature/bodies of water, or building/creating was noted as bringing relaxation in addition to a sense of accomplishment. Playing with others through organized sports or activities was highlighted as building relationships and a sense of security. Play in which there were no demands (e.g., playing with pets) was seen as facilitating peace and maintaining an orientation towards the present. Furthermore, participants noted the role of play in finding balance with the too hectic pace of life and that some cultures encourage or mandate relaxation and breaks from employment.

A second feature highlighted by participants was that play provides children a chance to be creative and express feelings and views of his or her world. Play in a non-judgemental and safe environment allows the child to express emotions and concerns freely, which leads to greater feelings of relaxation. For hospitalized children, play allows for self-expression, procedural coping, and comfort through familiar and safe activities (Jessee \& Gaynard, 2009).

\section{The Devaluation of Play}

The results of this study indicate that some caregivers from the Eastern cultural background consider play as useless, a waste of time, and not productive. They want their children to engage in play only when there is extra time, because doing homework is more important than play. Play is used by some to kill time. These caregivers downplay the importance of play because of cultural beliefs as supported by Kief and Casbergue (2000) who assert that the meaning and value of play are embedded in individuals' knowledge about play, their past experience with play, and their cultural values regarding play. Culture has a strong influence on how play developed in children, and how emotions are expressed and experienced during play (Chessa et al., 2013). Chessa and colleagues (2013) argue that some cultures diminish the importance of play, and it may not be an integral part of the life of the children. Children are taught to work productively and become responsible individuals. Therapists will face obstacles in their attempt to convince caregivers of the value of play when cultural beliefs are part of the equation, for caregivers prioritize study over play, academic success is more important. Play has to serve a function, in order to assert its significance.

\section{Conclusion \& Limitations}

Through current research interviewing play therapists worldwide regarding a global view of play, a new related description of play has developed. This definition highlights the importance of the power of play and its contribution to the evolving practice of therapy. The themes of global play that emerged (productivity, development, relationship, diversity, collaboration, technology, relaxation and devaluation) from the data, focus groups, and interviews from around the world can be used to inform future researchers and therapists, who study the value of play in the daily lives of children and their systems. Inherent within the methodological approach of naturalistic inquiry is the understanding that the results, both the substantive and formal grounded theories, are applicable to this study. As Lincoln and Guba (1985) indicate, "The only generalization is: there is no generalization... the trouble with generalizations is that they don't apply to particulars” (p. 110). However, this study provides results and discussions that can be used for further investigation, conceptualization, and inquiry into the issue of how diverse play is, and the application of play to the regular lives of people and their systems from a global perspective. 
The results of this study conclude that play is evolving, particularly because of the constant development of new technology. The complexity and evolving process of play has been observed on different continents, yet they exhibit similar characteristics as indicated through the thematic descriptions of this study. However, there are different lenses as to how play contributes to and is impeded by advancements in technology and structured play. "New information" found in this study suggests that with a devaluation of play in some locations, technology carries a negative connotation and yet, for other diverse groups, it is seen as enhancing productivity and attachment. Further studies will continue to answer the effects of technology on play and its effects on the freedom, relaxation and spontaneity of children's play.

It is important to understand the lens of each diverse location and group before concluding how play is seen and described in various communities across the globe. Furthermore, therapists must develop cultural competency in order to understand and address the "total child" within the context of child's ecosystem (O’Connor, 2000, p. 87). Caregivers' availability for play and involvement in therapy not only improves the child's environment, but also provides a better transition from the therapist's care. Caregivers need psychoeducation on the importance and values of play, so that children can learn social and negotiation skills; how to be a team player and to build attachments; to develop their imagination, creativity and unique identity; and to be de-stressed through play.

There are concerns about the appropriate use of technological applications in therapy. Technology can impact how therapy should be conducted and how therapists might be supervised. More research should be done on the use of multi-touch technologies, specifically in therapy with children. The paradoxical effect of technological play, however, suggests that a sense of being connected may be realized and yet one might experience a distance and feeling of disconnectedness without the face-to-face relationship.

Above all, therapists are wise to embrace a firm belief on the values and the healing power of play within the context of the ecosystem in order to truly know the child. With training and supervision, therapists can develop cultural competency, working with the total person from diverse communities.

Around the world children are thriving and others are merely surviving.... In different parts of the world children are encouraged to play, whether it be running in the streets of the Medina in Marrakech, playing with the latest technological tablets for self-expression, rolling a ball on a flat piece of land, or finding refuge in the hills. Play can facilitate relationships that are within the context of the environment of the child (p. 1)... How families facilitate a playful environment for relationship purposes and healing is as variable as the types of families around the world (p. 34) (Bowers, 2013).

\section{References}

Axline, V. (1947). Play therapy. New York: Ballantine Books.

Bowers, N. R. (2009). A naturalistic study of the early relationship development process of non-directive play therapy. International Journal of Play Therapy, 18(3), 186-204.

Bowers, N. R. (2013). Play therapy with families: A collaborative approach to healing. Lanham, Maryland: Rowman Littlefield. Boyd, D. (2014). It's complicated: The social lives of networked teens. Yale Press: New Haven.

Boyer, W. (2010). Getting to know O’Connor: Experiencing the ecosystemic play therapy model with urban First Nation people. The Family Journal: Counselling and Therapy for Couples and Families, 18(2), 202-207.

Braun, V., \& Clarke, V. (2006). Using thematic analysis in psychology. Qualitative Research in Psychology, 3, 77-101.

Brown, S. (2010). Play. New York: Penguin Group.

Chessa, D., Lis, A., Riso, D., Delvecchio, E., Mazzeschi, C., Russ, S., \& Dillon, J. (2013). A cross-cultural comparison of pretend play in U.S. and Italian children. Journal of Cross-Cultural Psychology, 44(4), 640-656. doi:10.1177/0022022112461853 
Cho, J., \& Lee, E. H. (2014). Reducing confusion about grounded theory and qualitative content analysis similarities and differences. The Qualitative Report, 19(64), 1-20.

Creswell, J. W. (1994). Research design: Qualitative and quantitative approaches. Thousand Oaks, C.A.: Sage Publications.

D’Angour, A. (2013). Plato and play: Taking education seriously in ancient Greece. American Journal of Play, 5(3), $293-307$.

Eichenbaum, A., Bavelier, D., \& Green, C. S. (2014). Video games: Play that can do serious good. American Journal of Play, 7(1), 50-72.

Elkind, D. (2008, Summer). The power of play: Learning what comes naturally. American Journal of Play, 1-6.

Fox, M. (2015). Brian Sutton-Smith, scholar of what's fun, dies at 90. New York Times, Obituaries, Sunday, March 15, 2015.

Gardner, H., \& Davis, K. (2013). The app generation: How today’s youth navigate identity, intimacy, and imagination in a digital world. Yale Press: New Haven.

Gaskins, S., Haight, W., \& Lancy, D. F. (2007). The cultural construction of play. In A. Göncü, \& S. Gaskins (Eds.), Play and development: Evolutionary, sociocultural, and functional perspectives (pp. 179-202). Mahwah, N.J.: Lawrence Erlbaum.

Göncü, A., Mistry, J., \& Mosier, C. (2000). Cultural variations in the play toddlers. International Journal of Behavioral Development, 24, 321-329.

Gaudiosi, J. (2012). New reports forecast global video game industry will reach $\$ 82$ billion by 2017. Forbes. Retrieved from http://www.forbes.com/sites/johngaudiosi/2012/07/18/news-report-forecasts-global-video-game-industry-will-reach-82-billio n-by-2017/.

Glaser, B., \& Straus, A. (1967). The discovery of grounded theory: Strategies for qualitative research. New York: Aldine de Gruyter.

Gold, K., Grothues, D., Jossberger, H., Gruber, H., \& Melter, M. (2014). Parents’ perceptions of play-therapeutic interventions to improve coping strategies of liver-transplanted children: A qualitative study. International Journal of Play Therapy, 23(3), 146-160.

Goodman, G., Reed, P., \& Athey-Lloyd, L. (2015). Mentalization and play therapy processes between two therapists and a child with Asperger's Disorder. International Journal of Play Therapy, 24(1), 13-29.

Henricks, T. (2008, Fall). The nature of play: An overview. American Journal of Play, 1(2),157- 180.

Jessee, P. O., \& Gaynard, L. (2009). Paradigms of play. In R. H. Thompson (Ed.), The handbook of child life: A guide for pediatric psychosocial care (pp. 136-159). Springfield, Il: Charles C. Thomas Publisher.

Kieff, J. E., \& Casbergue, R. M. (2000). Playful learning and teaching. Boston, MA: Allyn and Bacon.

Kraowski, P. (2012). Museum superheroes: The role of play in young children's lives. Journal of Museum Education, 37(1), 49-58.

Lancy, D. F. (2007). Accounting for variability in mother-child play. American Anthropologist, 109(2), 273-284.

Lincoln, Y., \& Guba, E. (1985). Naturalistic inquiry. Beverly Hills, CA: Sage.

Mahon, E. (1993). Play: Its role in child analysis, its fate in adult analysis. In A. Solnit, D. Cohen, P. Neubauer (Eds.), The Many meanings of play: A psychoanalytic perspective. New Haven: Yale University.

Marshall, C., \& Rossman, G. (1989). Designing qualitative research. Newbury Park, CA: Sage.

Meares, R. (1993). The metaphor of play. Northvale: Jason Aronson.

Merriam-Webster Online Dictionary. (2012, 2015). Retrieved from http://www.merriam-webster.com/dictionary/play

Morris, R. (1981). Old English homilies of twelfth century. New York: Kraus. Reprint.

O’Connor, K. J. (2000). The play therapy primer (2nd ed.). New York: Wiley.

Parmar, P., Harkness, S., \& Super, C. M. (2004). Asian and Euro-American parents' ethno-theories of play and learning: Effects on preschool children's home routines and school behavior. International Journal of Behavioral Development, 28, 97-104.

Perry, B., \& Szalavitz, M. (2007). The boy who was raised as a dog. New York: Basic Books.

Penn, S., \& Post, P. (2014). Investigating various dimensions of play therapists' self-reported multicultural counseling competence. International Journal of Play Therapy, 21(1).

Pykhtina, O. (2014, Fall). Computerized toys in play therapy: A barrier of an opportunity? Playground, 4-7.

Riedel Bowers, N. (2009). A naturalistic study of the early relationship development process of non-directive play therapy. International Journal of Play Therapy, 18(3), 186-204.

Riedel Bowers, N. (2013). Play therapy with families: A collaborative approach to healing. Lanham, Maryland: Rowman Littlefield.

Rideout, V. J., Foehr, U. G., \& Roberts, D. F. (2010). Generation M2-Media in the lives of 8- to 18-year olds (Report, Kaiser Family Foundation, 2010). Retrieved from http://kff.org/other/poll-finding/report-generation-m2-i-the-lives/ 
Roopnarine, J. L., \& Davidson, K. L. (2015). Parent-child play across culture: Advancing play research. American Journal of Play, $7(2), 228-252$.

Russ, S., \& Niec, L. (2011). Play in clinical practice. New York: Guilford Press.

Russ, S. W., Fiorelli, J., \& Spannagel, S. C. (2011). Cognitive and affective processes in play. In S. W. Russ, \& L. N. Niec (Eds.), Play in clinical practice: Evidence-based approaches (pp. 3-22). New York, NY: Guilford Press.

Singer, D. G., Singer, J. L., D’Agostino, H., \& DeLong, R. (2009). Children’s pastime and play in Sixteen Nations: Is free-play declining? American Journal of Play, 1, 283-312.

Snow, M., Winburn, A., Crumrine, L., Jackson, E., \& Killian. (2012). The iPad playroom: A therapeutic technique. Play Therapy 7(3), 16-19.

Sutton-Smith, B. (2008, Summer). Play theory: A personal journey and new thoughts. American Journal of Play, 83-125.

Taylor, S. I., Rogers, C. S., Dodd, A. T., Kaneda, T., Nagasaki, I., Watanabe, Y., \& Goshiki, T. (2004). The meaning of play: A cross-cultural study of American and Japanese teachers' perspective on play. Journal of Early Childhood Teacher Education, 24, 311-321. 